\title{
Influence of growth conditions on production of poly(3-hydroxybutyrate) by Bacillus cereus HAL 03 endophytic to Helianthus annuus L.
}

\author{
Rituparna Das ${ }^{1}$, Agnijita Dey ${ }^{1}$, Arundhati Pal ${ }^{2}$, A. K. Paul ${ }^{1 *}$ \\ ${ }^{1}$ Microbiology Laboratory, Department of Botany, University of Calcutta, 35, Ballygunge Circular Road, Kolkata 700 019, India. \\ ${ }^{2}$ Post Graduate Department of Botany, Serampore College, 9, William Carey Road, Serampore, Hooghly 712 201, India.
}

\begin{tabular}{|c|c|}
\hline ARTICLE INFO & ABSTRACT \\
\hline $\begin{array}{l}\text { Article history: } \\
\text { Received on: } 11 / 05 / 2016 \\
\text { Revised on: } 06 / 07 / 2016 \\
\text { Accepted on: } 24 / 07 / 2016 \\
\text { Available online: } 26 / 08 / 2016 \\
\end{array}$ & $\begin{array}{l}\text { Systematic screening of culturable endophytic bacteria for production of poly }(3 \text {-hydroxybutyric acid) }[\mathrm{P}(3 \mathrm{HB})] \\
\text { has resulted in the isolation of a potent strain identified as Bacillus cereus HAL 03 (GenBank Accession No. } \\
\text { KR } 869088) \text { from leaf tissue of Helianthus annuus L. Production of } \mathrm{P}(3 \mathrm{HB}) \text { by this strain was influenced } \\
\text { significantly by the quality as well as quantity of suitable carbon and nitrogen sources in the growth medium. At } \\
2 \%(\mathrm{w} / \mathrm{v}) \text { sucrose, the accumulated } \mathrm{P}(3 \mathrm{HB}) \text { reached to a level of } 50.46 \% \text { of its cell dry weight }(\mathrm{CDW}) \text {, whereas }\end{array}$ \\
\hline $\begin{array}{l}\text { Key words: } \\
\text { Bacillus cereus, bacterial } \\
\text { endophytes, biodegradable } \\
\text { polyester, Helianthus annuus } \\
\text { L., polyhydroxyalkanoates, } \\
\text { poly(3-hydroxybutyrate). }\end{array}$ & $\begin{array}{l}\text { yeast extract }(0.2 \%) \text { as nitrogen source enhanced } \mathrm{P}(3 \mathrm{HB}) \text { production and accounted for } 53.19 \% \text { of CDW. } \\
\text { Moreover, the non-conventional carbon sources such as molasses further increased the production of the } \\
\text { polyester up to } 54.05 \% \text { of its CDW. Finally, the identity of this intracellularly accumulated polyester was } \\
\text { confirmed as a homopolymer of } 3 \text { (hydroxybutyric acid) by the Fourier-transform infrared and proton nuclear } \\
\text { magnetic resonance spectroscopic analysis. This study appears to indicate the first ever report of } \mathrm{P}(3 \mathrm{HB}) \\
\text { production by any strain of B. cereus endophytic to H. annuus L. }\end{array}$ \\
\hline
\end{tabular}

\section{INTRODUCTION}

Polyhydroxyalkanoates (PHAs) are linear biopolyesters of hydroxyalkanoic acids, which are biodegradable and biocompatible in nature and have the potential to act as bioplastics due to their physical and material properties analogous to synthetic plastics [1]. They are produced by a wide variety of microorganisms and are accumulated as intracellular inclusions or granules mostly under conditions of unbalanced growth [2]. To make the PHA bioplastic production economically viable and competitive with petroleum based thermoplastics, efforts are being made to find newer highyielding microbial strains and also to develop low-cost production strategies.

\footnotetext{
* Corresponding Author

A. K. Paul, Microbiology Laboratory, Department of Botany, University of Calcutta, Kolkata 700 019, India.Email: amalk_paul@yahoo.co.in Mob: 919830905580, Fax: 9103324614849
}

Plant offers a wide range of habitats that support microbial growth and the diversity of bacteria associated with the plants have been reported to accumulate PHAs including the most widely studied poly(3-hydroxybutyric acid) $[\mathrm{P}(3 \mathrm{HB})]$. While, the plant rhizosphere is an interesting hidden niche for polyhydroxyalkanoate producers $[3,4,5]$, the culturable diversity of bacteria endophytic to plants have attracted the attention in recent years for the production of PHAs. Catalan et al. [6] have reported the accumulation of $\mathrm{P}(3 \mathrm{HB})$ in the diazotrophic endophyte Herbaspirillum seropedicae Z69 colonizing a variety of higher plants. The bacterium accumulated $36 \%$ of its biomass as $\mathrm{P}(3 \mathrm{HB})$ when grown in glucose containing medium. Comparative studies on the effects of heavy metals on endophytic and non-endophytic strains of Azospirillum brasilense [7], have revealed that nonendophytic strain of $A$. brasilense sp7 accumulated higher amount of $\mathrm{P}(3 \mathrm{HB})$ than that of the endophytic strain of $A$. brasilense sp245 in response to heavy metals. Occurrence of endophytic bacteria in Helianthus annuиs L., the important oil-yielding plant is not an exception and includes Achromobacter xiloxidans, Alcaligenes sp. and Bacillus pumilus, which so far have not been reported to synthesize and accumulate the polyester, $\mathrm{P}(3 \mathrm{HB})[8]$. 
Production of $\mathrm{P}(3 \mathrm{HB})$ by members of the genus Bacillus has been reported extensively and found to be associated with their growth being influenced by various physico-chemical parameters. However, synthesis of $\mathrm{P}(3 \mathrm{HB})$ by Bacillus spp. utilizing variety of readily available cost-effective substrates has been met with limited success for large scale production $[9,10]$. Moreover, imbalance of nutritional conditions in Bacillus spp. have often been found to result in sporulation concomitant with reduction of $\mathrm{P}(3 \mathrm{HB})$ production. Such a situation could be nullified by optimization of growth medium constituents as well as physical parameters. The ratio of carbon and nitrogen as well as the $\mathrm{pH}$ of the medium exert significant influence on the metabolism and accumulation of $\mathrm{P}(3 \mathrm{HB})$ by Bacillus cereus. Synthesis and accumulation of $\mathrm{P}(3 \mathrm{HB})$ by strains of $B$. cereus utilizing different carbon sources have been accounted for about $50 \%$ of CDW [1019]. Moreover, production of co-polymers of 3-hydroxybutyric acid and 3-hydroxyvaleric acid, hydroxybutyric and hydroxycaproic acid and $\mathrm{P}(3 \mathrm{HB})$ tercopolymers by strains of $B$. cereus are not uncommon $[11,13,14]$.

In the course of our study of culturable endophytic bacteria isolated from $H$. annuus $\mathrm{L}$. for production of poly(3hydroxybutyrate), a leaf endophytic bacterium B. cereus HAL 03 most suitable for $\mathrm{P}(3 \mathrm{HB})$ production has been selected, characterized in details and identified. Nutritional and cultural conditions including the utilization of non-conventional carbon sources by the isolate have been optimized for production of $\mathrm{P}(3 \mathrm{HB})$ under batch cultivation and the identity of the polyester has been confirmed by spectroscopic analysis.

\section{MATERIALS AND METHODS}

\subsection{Bacterial cultures and maintenance}

The culturable endophytic bacterial strains used in this study were isolated from the surface sterilized leaf, stem and root segments of freshly collected $H$. аппии $\mathrm{L}$. plants following the techniques of Hallmann et al. [20] and Reinhold-Hurek and Hurek [21]. Pure cultures of these isolates were maintained at $4^{\circ} \mathrm{C}$ on slopes of tryptic soy agar by subculturing at regular interval.

\subsection{Characterization of the bacterial isolate}

The endophytic bacterial isolate was characterized and identified following standard morphological, physiological and biochemical tests [22] including susceptibility to different antibiotics [23]. The 16S rRNA gene sequence was determined by direct sequencing of PCR amplified 16S rDNA. The genomic DNA was isolated and purified according to the modified method of Marmur [24] and the 16S rDNA was amplified using the universal primers $8 \mathrm{~F}$ (5'AGAGTTTGATCCTGGCTCAG3') and 1492R (5'GTTACCTTGTTACGACTT3'). The PCR amplified product was purified using QIAquick gel extraction kit (Qiagen, Netherlands) and the sequencing reaction was performed with ABI PRISM Dye Terminator cycle-sequencing ready reaction kit (Applied Biosystems). The sequencing products were purified and electrophoresed on polyacrylamide sequencing gel using an ABI
377 automated DNA sequencer. Sequencing data were analyzed by $\mathrm{ABI}$ version 3.0.1 b3 software and compared with reference sequences using the NCBI BLASTN programme. Multiple sequence alignments were carried out by using BLOSUM 62 matrix with the program package Clustal-W employing the neighbor-joining algorithm method [25] with MEGA version 6.0.

\subsection{Growth and $\mathrm{P}(3 \mathrm{HB})$ production}

Growth and $\mathrm{P}(3 \mathrm{HB})$ production by bacterial endophytes were carried out in mineral salts medium [26]. The medium $(50 \mathrm{ml}$ / $250 \mathrm{ml}$ Erlenmeyer flask) was inoculated with freshly prepared inoculum at $1 \%$ level and incubated on a rotary shaker (120 rpm) at $32^{\circ} \mathrm{C}$. Growth and $\mathrm{P}(3 \mathrm{HB})$ content of the cell dry weight $(\mathrm{CDW})$ were determined at regular time interval. While, growth of the isolates was estimated by the dry weight method, $\mathrm{P}(3 \mathrm{HB})$ content of acetone dried cell mass was determined as per the method described by Law and Slepeckey [27]. Glucose in the medium was estimated following dinitrosalicylic acid method [28]. The percentage of sporulating cells was determined at regular time interval following examination of wet mounts of culture under phase contrast microscope (Carl Zeiss No. 288997).

\subsection{FTIR spectral analysis}

For Fourier transform infrared (FTIR) spectroscopy, the purified polyester isolated from the bacterial isolate HAL 03 was prepared as $\mathrm{KBr}$ pellet and scanned in a Perkin Elmer RX-1 FTIR spectrophotometer in the range of 4500 to $500 \mathrm{~cm}^{-1}[7,29]$.

\section{5. ${ }^{1} \mathrm{H}$ NMR analysis}

Monomer composition of the purified polyester was determined by proton nuclear magnetic resonance $\left({ }^{1} \mathrm{H}\right.$ NMR) spectroscopy. The polyester was dissolved in deuterochloroform $\left(\mathrm{CDCl}_{3}\right)$ and subjected to ${ }^{1} \mathrm{H}$ NMR analysis in a Bruker AV300 Supercon NMR spectrophotometer working in digital mode. A 5 $\mathrm{nm}$ BBO probe head at 30-degree flip angle was used. The chemical shift-scale was in parts per million and tetramethylsilane $\left(\mathrm{Me}_{4} \mathrm{Si}\right)$ was used as the internal standard.

\section{RESULTS AND DISCUSSION}

\subsection{Screening and selection of endophytic bacteria for $\mathbf{P}(3 \mathrm{HB})$ production}

Occurrence of endophytic bacteria with special reference to production of jasmonates and abscisic acid in culture has been well documented in $H$. annuus L. by Forchetti et al. [8]. The present study is an attempt to explore the potential of bacteria endophytic of $H$. annuus $\mathrm{L}$. for the production of biodegradable biopolyester P(3HB). During the course of this study, a total of 23 phenotypically distinguishable endophytic bacterial isolates were obtained from the surface sterilized leaf, stem and root tissues of $H$. annuus $\mathrm{L}$. and screened for the intracellular accumulation of $\mathrm{P}(3 \mathrm{HB})$ during growth following chemical estimation method of Law and Slepeckey [27]. Growth associated $\mathrm{P}(3 \mathrm{HB})$ accumulation was recorded in about $43.5 \%$ of the total endophytic isolates and 
the $\mathrm{P}(3 \mathrm{HB})$ content of these positive isolates ranged from 4.72 $34.36 \%$ of their cell dry weight (CDW). These findings received support from the production of $\mathrm{P}(3 \mathrm{HB})$ by endophytic diazotrophs $[6,7]$ as well as heterotrophs [30]. Out of these 23 isolates, bacterial strain HAL 03, endophytic to leaf of $H$. annuus $\mathrm{L}$. appeared to be the most promising one showing the highest intracellular accumulation of polyester ( $34.36 \%$ of CDW) and was selected for detailed studies.

\subsection{Characterization and identification of the strain HAL 03}

Morphological, physiological and biochemical characteristics of the strain HAL 03 were determined following the standard protocol. The isolate HAL 03, a rod-shaped, motile, aerobic, Gram-positive, endospore forming bacterium was found to tolerate wide range of $\mathrm{pH}(3.5-8.0)$, temperature $\left(25-42^{\circ} \mathrm{C}\right)$ and $\mathrm{NaCl}(5-10 \%)$. It also produced a number of hydrolytic enzymes and showed characteristic pattern of sugar fermentation as well as sensitivity to a number of antibacterial antibiotics (Table 1). Based on these features, the strain HAL 03 was placed in the genus Bacillus. The 16S rDNA fragment of Bacillus HAL 03 was amplified by PCR using universal primers $8 \mathrm{~F}$ and $1492 \mathrm{R}$ and a single discrete PCR amplicon band of approximately $1200 \mathrm{bp}$ was resolved in an agarose gel. The PCR amplicon was further purified and sequenced in an ABI 377 automated DNA sequencer. The 16S rDNA sequence analysis revealed that the strain HAL 03 was most closely related to Bacillus cereus strain JCM 2152 with a very high sequence similarity (99\%), reasonably high score and e-value being zero. Phylogenetically the strain showed close relationship with Bacillus pseudomycoides, B. toyonensis and B. thuringiensis along with a number of related species (Table 2). The evolutionary relationship as depicted from the dendrogram showed clear rooted evolution (Figure 1). The $16 \mathrm{~S}$ rDNA sequence of the isolate HAL 03 has been deposited to the GenBank under the accession number KR869088 and designated as Bacillus cereus HAL 03.

Biosynthesis and characterization of $\mathrm{P}(3 \mathrm{HB})$ by native strains of $B$. cereus have been investigated using variety of raw materials $[9,10]$. Further efforts have also been made for the large scale production and efficient recovery of $\mathrm{P}(3 \mathrm{HB})$ [10]. This study is probably the first ever report of the polyester production by any $B$. cereus strains endophytic to $H$. annuus $\mathrm{L}$.

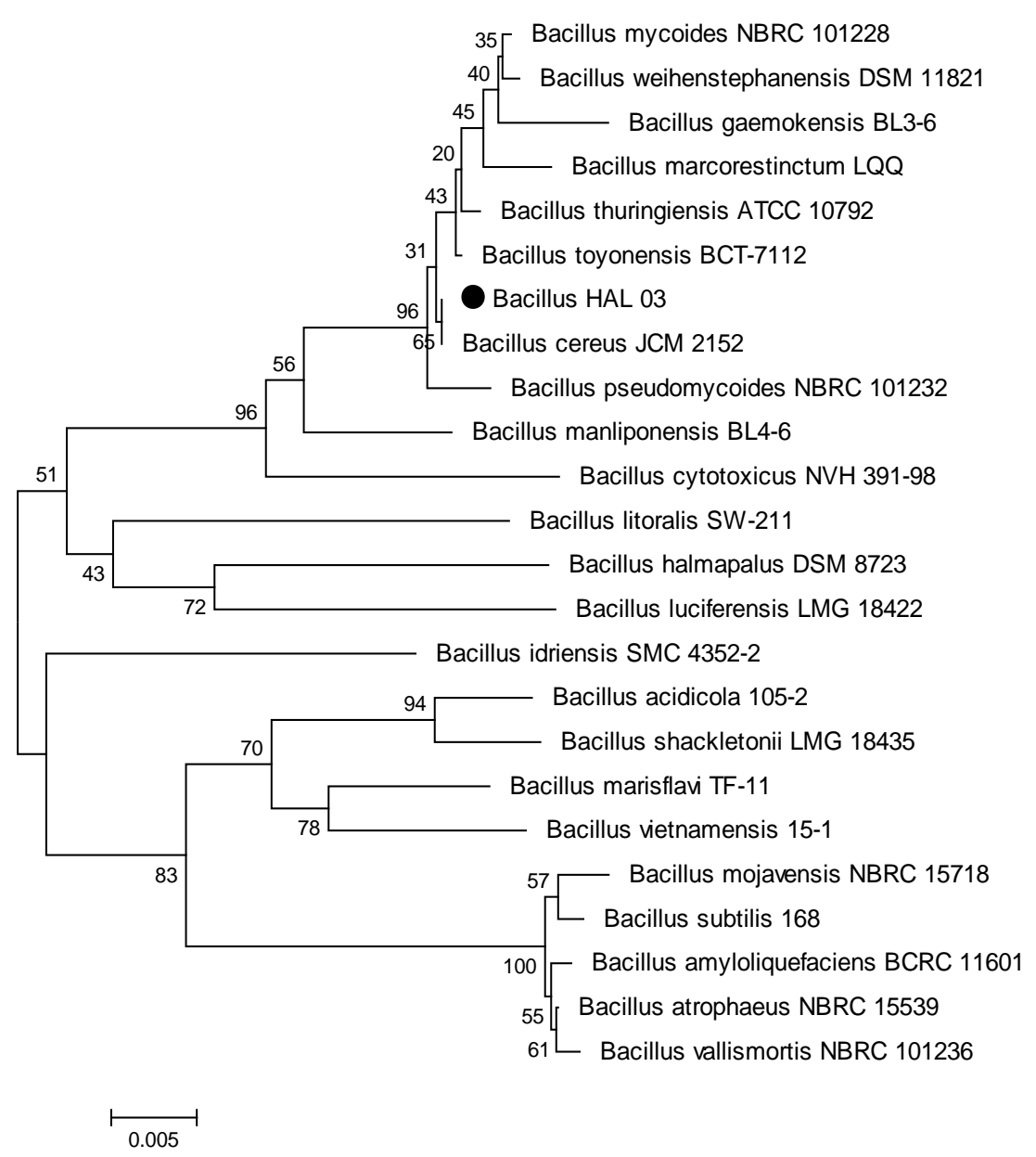

Fig. 1: Phylogenetic relationship of Bacillus HAL 03 (GenBank Accession Number KR869088) endophytic to Helianthus annuus L. with closely allied Bacillus spp. based on $16 \mathrm{~S}$ rDNA sequence analysis. 
Table 1: Morphological, physiological and biochemical characters of the bacterial strain HAL 03 endophytic to leaf tissues of $H$. annииs L.

\begin{tabular}{|c|c|}
\hline Characters & Response \\
\hline \multicolumn{2}{|l|}{ Morphological characteristics } \\
\hline Colony morphology & White, round with smooth margin \\
\hline Cell morphology & Rod-shaped, single, $2.75 \mu \mathrm{m} \times 1.25 \mu \mathrm{m}$ \\
\hline Gram reaction & Gram (+) positive \\
\hline Endospore formation & + \\
\hline Motility & + \\
\hline Diffusible pigment production & None \\
\hline \multicolumn{2}{|l|}{ Physiological characteristics } \\
\hline Growth under aerobic condition & + \\
\hline Growth under anaerobic condition & - \\
\hline Growth on Mac Conkey agar & - \\
\hline Range of $\mathrm{pH}$ for growth & 3.5-8.0, optimum 7.6 \\
\hline Range of temperature for growth & $25-42^{\circ} \mathrm{C}$, optimum $37^{\circ} \mathrm{C}$ \\
\hline $\mathrm{NaCl}$ tolerance & $5-10 \%(\mathrm{w} / \mathrm{v})$ \\
\hline \multicolumn{2}{|l|}{ Biochemical characteristics } \\
\hline Production of catalase & + \\
\hline Production of lipase & + \\
\hline Production of cellulase & - \\
\hline Production of pectinase & + \\
\hline Hydrolysis of starch & + \\
\hline Hydrolysis of casein & + \\
\hline Liquefaction of gelatin & + \\
\hline Reduction of nitrate & - \\
\hline Production of acid from & Glucose, sucrose, fructose, maltose and galactose \\
\hline Unable to ferment & Mannitol, lactose, xylose and sorbitol \\
\hline Sensitive to antibiotics & Erythromycin, chlorotetracycline, vancomycin, methicillin, ciprofloxacin, kanamycin, gentamycin and penicillin \\
\hline Resistant to antibiotics & Ampicillin and bacitracin \\
\hline
\end{tabular}

Table 2: $16 \mathrm{~S}$ rDNA sequence homology of Bacillus cereus HAL 03 (GenBank Accession Number KR869088) with closely related sequences from databases using BLAST analysis.

\begin{tabular}{|c|c|c|c|c|c|c|}
\hline Description & Max score & Total score & Query cover & E value & Ident & Accession \\
\hline Bacillus cereus strain JCM 2152 & 1386 & 1386 & $100 \%$ & 0.0 & $99 \%$ & NR113266.1 \\
\hline Bacillus pseudomycoides strain NBRC 101232 & 1371 & 1371 & $100 \%$ & 0.0 & $99 \%$ & NR113991.1 \\
\hline Bacillus toyonensis strain BCT-7112 & 1368 & 1368 & $100 \%$ & 0.0 & $99 \%$ & NR121761.1 \\
\hline Bacillus thuringiensis strain ATCC 10792 & 1368 & 1368 & $100 \%$ & 0.0 & $99 \%$ & NR114581.1 \\
\hline Baciilus mycoides strain NRBC 101228 & 1362 & 1362 & $100 \%$ & 0.0 & $99 \%$ & NR113990.1 \\
\hline Bacillus weihenstephanensis strain DSM 11821 & 1362 & 1362 & $100 \%$ & 0.0 & $99 \%$ & NR024697.1 \\
\hline Bacillus cytotoxicus strain NVH 391-98 & 1287 & 1287 & $100 \%$ & 0.0 & $97 \%$ & NR074914.1 \\
\hline Bacillus manliponensis strain BL4-6 & 1283 & 1283 & $95 \%$ & 0.0 & $98 \%$ & NR125530.1 \\
\hline Bacillus gaemokensis strain BL3-6 & 1247 & 1247 & $91 \%$ & 0.0 & $99 \%$ & NR116644.1 \\
\hline Bacillus marcorestinctum strain LQQ & 1187 & 1187 & $87 \%$ & 0.0 & $99 \%$ & NR117414.1 \\
\hline Bacillus litolaris strain SW-211 & 1178 & 1178 & $100 \%$ & 0.0 & $94 \%$ & NR043015.1 \\
\hline Bacillus acidicola strain 105-2 & 1173 & 1173 & $100 \%$ & 0.0 & $93 \%$ & NR041942.1 \\
\hline Bacillus halmapalus strain DSM 8723 & 1168 & 1168 & $100 \%$ & 0.0 & $93 \%$ & NR026144.1 \\
\hline Bacillus luciferensis strain LMG 18422 & 1166 & 1166 & $100 \%$ & 0.0 & $93 \%$ & NR025511.1 \\
\hline Bacillus marisflavi strain TF-11 & 1162 & 1162 & $100 \%$ & 0.0 & $93 \%$ & NR025240.1 \\
\hline Bacillus shackletonii strain LMG 18435 & 1160 & 1160 & $100 \%$ & 0.0 & $93 \%$ & NR025373.1 \\
\hline Bacillus atrophaeus strain NBRC 15539 & 1157 & 1157 & $100 \%$ & 0.0 & $93 \%$ & NR112723.1 \\
\hline Bacillus valismortis strain NBRC 101236 & 1153 & 1153 & $100 \%$ & 0.0 & $93 \%$ & NR113994.1 \\
\hline Bacillus amyloliquefaciens strain BCRC 11601 & 1153 & 1153 & $100 \%$ & 0.0 & $93 \%$ & NR 116022.1 \\
\hline Bacillus idriensis strain SMC 4352-2 & 1153 & 1153 & $98 \%$ & 0.0 & $93 \%$ & NR043268.1 \\
\hline Bacillus vietnamensis strain $15-1$ & 1153 & 1153 & $100 \%$ & 0.0 & $93 \%$ & NR024808.1 \\
\hline Bacillus mojavensis strain NBRC 15718 & 1148 & 1148 & $100 \%$ & 0.0 & $93 \%$ & NR112725.1 \\
\hline Bacillus subtilis strain 168 & 1142 & 1142 & $100 \%$ & 0.0 & $93 \%$ & NR102783.1 \\
\hline
\end{tabular}

\subsection{Effect of different media on $\mathrm{P}(3 \mathrm{HB})$ production}

Four culture media of different composition were used to determine the most suitable one supporting growth and maximum $\mathrm{P}(3 \mathrm{HB})$ accumulation by $B$. cereus HAL 03 . Maximum biomass production $(2.32 \mathrm{~g} / \mathrm{l})$ as well as $\mathrm{P}(3 \mathrm{HB})$ accumulation $(34.36 \%$, CDW) were best supported by the components of mineral salts -medium as reported earlier by Ramsay et al. [26]. Likewise, amino acids present in glucose-casamino acid medium might have contributed to growth associated polymer accumulation. On the other hand, tris-glucose medium could not provide sufficient nutritional support for production of biomass as well as polyester by the endophytic strain (Figure 2). 


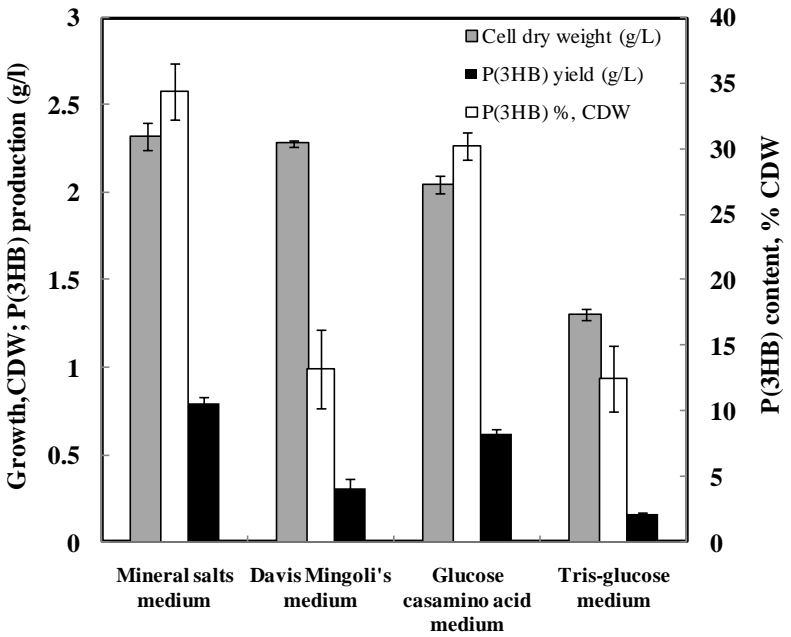

Fig. 2: Effect of different media on growth and production of poly(3-hydroxybutyrate) by the bacterial isolate B. cereus HAL 03
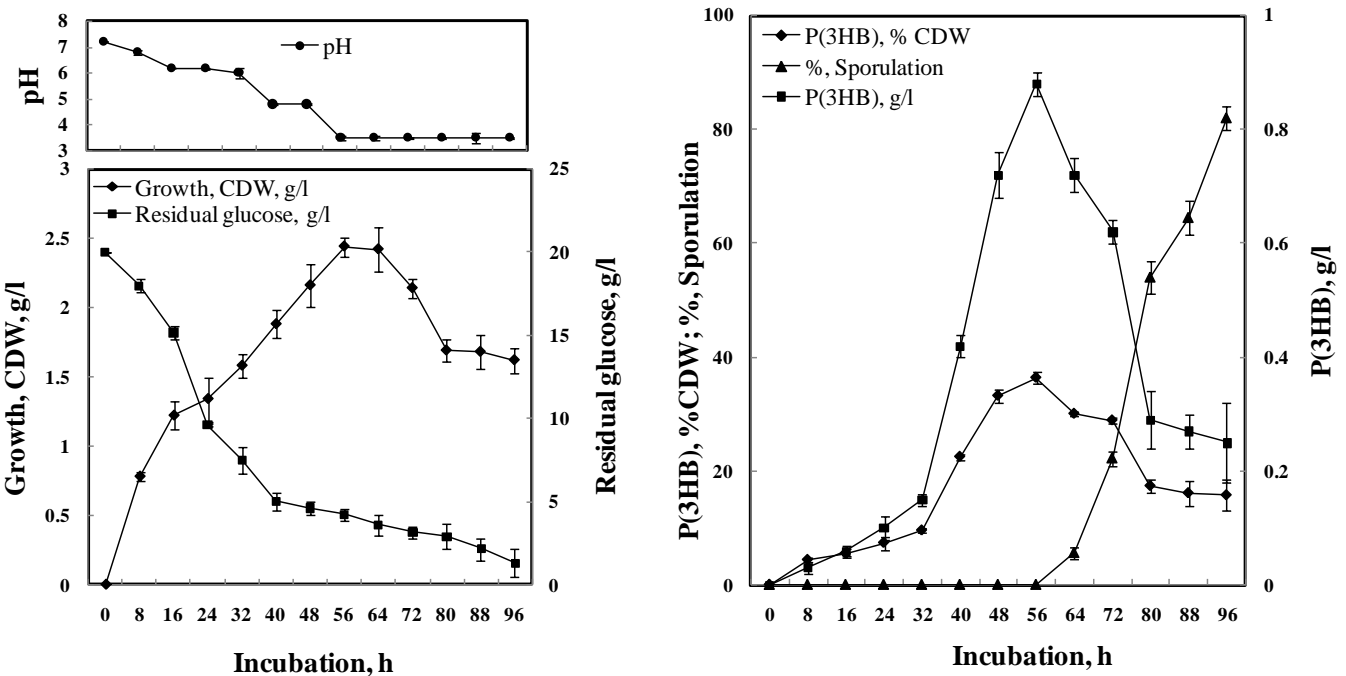

Fig. 3: Time course of growth, glucose utilization, changes in $\mathrm{pH}$, poly(3-hydroxybutyrate) production, yield and sporulation by the bacterial isolate B. cereus HAL 03.

\subsection{Time course of growth and $\mathrm{P}(3 \mathrm{HB})$ accumulation}

Time course of growth and $\mathrm{P}(3 \mathrm{HB})$ accumulation by $B$. cereus HAL 03 showed that intracellular accumulation of $\mathrm{P}(3 \mathrm{HB})$ was more or less parallel with growth and maximum $\mathrm{P}(3 \mathrm{HB})$ accumulation $(36.38 \%, \mathrm{CDW})$ was recorded after $56 \mathrm{~h}$ of incubation under continuous shaking (Figure 3). This is indicative of the fact that like many other heterotrophic bacteria, nutrient limitation is not an essential requirement for triggering $\mathrm{P}(3 \mathrm{HB})$ production in B. cereus HAL 03. Furthermore, biosynthesis and accumulation of $\mathrm{P}(3 \mathrm{HB})$ by HAL 03 was accompanied with the rapid utilization of glucose and as a consequence, the medium turned acidic ( $\mathrm{pH} 3.5)$. Such decline in $\mathrm{pH}$ of the culture medium may possibly be due to the production of several acidic metabolic intermediates during growth. It has also been revealed that the accumulation of $\mathrm{P}(3 \mathrm{HB})$ along with growth reached a maximum (56 h) just prior to the onset of sporulation, which received support from the earlier findings of Benoit et al. [31]. About $82 \%$ of cells showed mature spores at the end of $96 \mathrm{~h}$ of incubation. The formation of mature endospores in growing cells was associated with rapid decline of intracellular polymer indicating its possible utilization as carbon and energy source for sporogenesis. Delay in sporulation (initiation after $56 \mathrm{~h}$ ) could be attributed to the presence of excess carbon as well as synthetic medium ingredients which probably regulated the flux of metabolic intermediates towards growth associated biosynthesis of $\mathrm{P}(3 \mathrm{HB})$ by the present strain [32].

\subsection{Effect of carbon source}

The bacterium efficiently utilized glycerol, sucrose, maltose, fructose, mannitol, glucose and acetate for growth but higher polymer production and yield was observed in sucrose $(50.46 \%, \mathrm{CDW})$ followed by fructose $(46.44 \%, \mathrm{CDW})$ and glucose $(34.36 \%$, CDW) (Table 3$)$.

At an optimum concentration of sucrose $(2 \%, w / v)$, the production and yield of $\mathrm{P}(3 \mathrm{HB})$ were $50.83 \%$ and $1.37 \mathrm{~g} / \mathrm{l}$ respectively. Further increase of sucrose in the medium was inhibitory to both growth and polymer accumulation (Figure 4). 
Table 3: Growth and production of poly(3-hydroxybutyrate) by the endophytic bacterium B. cereus HAL 03 in various carbon sources.

\begin{tabular}{|c|c|c|c|}
\hline \multirow{2}{*}{$\begin{array}{c}\text { Carbon source } \\
2 \%(\mathrm{w} / \mathrm{v})\end{array}$} & \multirow{2}{*}{ Growth, CDW, g/l } & \multicolumn{2}{|c|}{$\mathbf{P}(3 \mathrm{HB})$ production } \\
\hline & & $\mathrm{P}(3 \mathrm{HB}), \% \mathrm{CDW}$ & $\mathbf{P}(3 \mathrm{HB}), \mathrm{g} / \mathrm{l}$ \\
\hline Glucose & $2.32 \pm 0.02$ & $34.36 \pm 2.2$ & $0.79 \pm 0.04$ \\
\hline Fructose & $2.53 \pm 0.07$ & $46.44 \pm 1.7$ & $1.17 \pm 0.11$ \\
\hline Sucrose & $2.65 \pm 0.14$ & $50.46 \pm 3.1$ & $1.34 \pm 0.12$ \\
\hline Maltose & $2.65 \pm 0.11$ & $26.74 \pm 0.3$ & $0.70 \pm 0.03$ \\
\hline Galactose & $0.75 \pm 0.09$ & $29.76 \pm 0.5$ & $0.22 \pm 0.05$ \\
\hline Mannitol & $2.53 \pm 0.05$ & $27.32 \pm 1.2$ & $0.69 \pm 0.06$ \\
\hline Glycerol & $3.53 \pm 0.07$ & $23.58 \pm 1.4$ & $0.83 \pm 0.09$ \\
\hline Sodium acetate & $2.25 \pm 0.16$ & $09.37 \pm 0.3$ & $0.21 \pm 0.05$ \\
\hline Sodium citrate & $1.73 \pm 0.05$ & $12.59 \pm 0.8$ & $0.22 \pm 0.04$ \\
\hline Sodium gluconate & $0.88 \pm 0.08$ & $08.57 \pm 1.6$ & $0.07 \pm 0.12$ \\
\hline
\end{tabular}

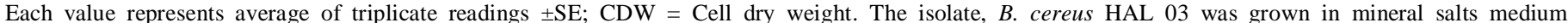

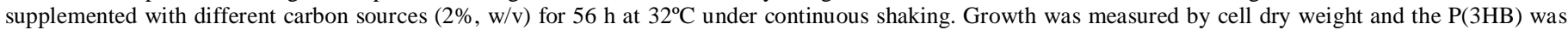
extracted with chloroform from acetone dried cell mass and quantified according to Law and Slepeckey [27].

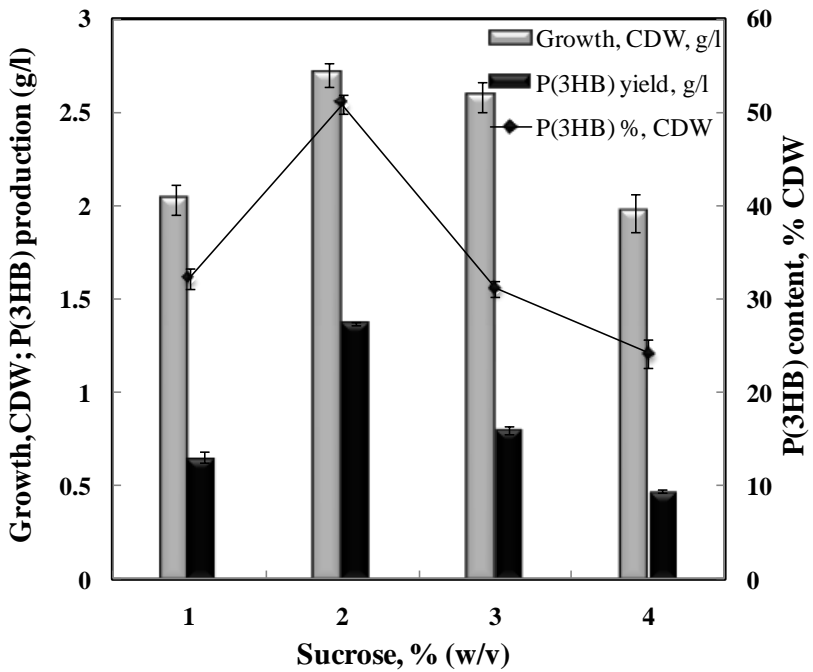

Fig. 4: Effect of sucrose concentrations on growth and production of poly(3-hydroxybutyrate) by the bacterial isolate B. cereus HAL 03 .

Table 4: Growth and production of poly(3-hydroxybutyrate) by the endophytic bacterium B. cereus HAL 03 in various nitrogen sources.

\begin{tabular}{|c|c|c|c|}
\hline \multirow{2}{*}{$\begin{array}{c}\text { Nitrogen source } \\
0.1 \%(w / v)\end{array}$} & \multirow{2}{*}{$\begin{array}{l}\text { Growth, } \\
\text { CDW, g/l }\end{array}$} & \multicolumn{2}{|c|}{$\mathbf{P}(3 \mathrm{HB})$ production } \\
\hline & & P(3HB $), \%$ CDW & P(3HB $), \mathrm{g} / \mathrm{l}$ \\
\hline Beef extract & $1.75 \pm 0.04$ & $43.70 \pm 1.23$ & $0.76 \pm 0.04$ \\
\hline Bactopeptone & $1.80 \pm 0.08$ & $31.34 \pm 1.89$ & $0.56 \pm 0.15$ \\
\hline Yeast extract & $1.98 \pm 0.12$ & $48.83 \pm 2.01$ & $0.96 \pm 0.25$ \\
\hline Casamino acid & $1.25 \pm 0.03$ & $18.52 \pm 2.07$ & $0.23 \pm 0.06$ \\
\hline Tryptone & $1.68 \pm 0.03$ & $19.55 \pm 0.34$ & $0.33 \pm 0.01$ \\
\hline Ammonium sulfate & $2.32 \pm 0.02$ & $34.36 \pm 2.2$ & $0.79 \pm 0.04$ \\
\hline Ammonium nitrate & $0.92 \pm 0.10$ & $23.86 \pm 1.19$ & $0.22 \pm 0.12$ \\
\hline Ammonium chloride & $1.35 \pm 0.12$ & $7.46 \pm 1.34$ & $0.10 \pm 0.16$ \\
\hline Sodium nitrate & $1.23 \pm 0.02$ & $27.31 \pm 0.85$ & $0.34 \pm 0.01$ \\
\hline
\end{tabular}

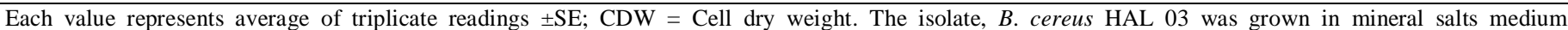

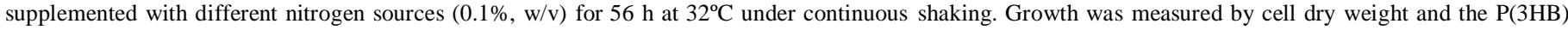
was extracted with chloroform from acetone dried cell mass and quantified according to Law and Slepeckey [27].

\subsection{Effect of nitrogen source}

Among the different inorganic and organic nitrogen sources tested, ammonium sulfate resulted in significant increase in biomass formation, while yeast extract promoted the production of $\mathrm{P}(3 \mathrm{HB})$ (Table 4). Further increase of yeast extract in the medium resulted enhanced growth and polyester production and maximum $\mathrm{P}(3 \mathrm{HB})$ accumulation $(53.2 \%, \mathrm{CDW})$ was recorded at $0.2 \%$ yeast extract (Figure 5$)$. However, the yield of $\mathrm{P}(3 \mathrm{HB})$ in ammonium sulfate $(0.79 \mathrm{~g} / \mathrm{l})$ was comparable with that in beef extract $(0.76 \mathrm{~g} / \mathrm{l})$. 


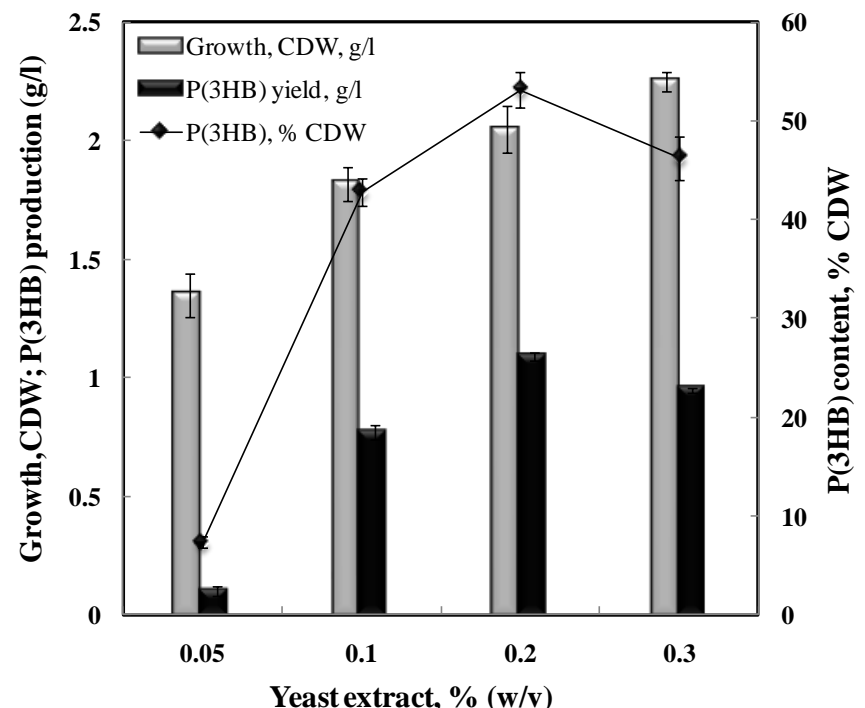

Fig. 5: Effect of different concentrations of yeast extract on growth and production of poly(3-hydroxybutyrate) by the bacterial isolate B. cereus HAL 03 .
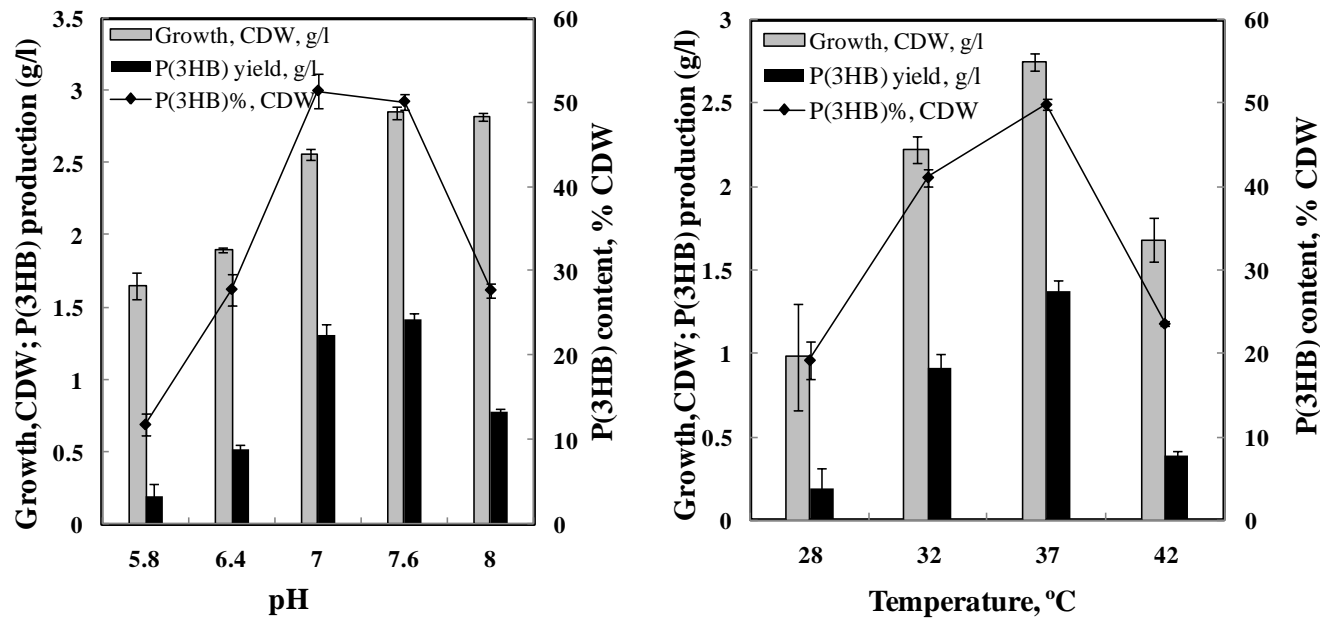

Fig. 6: Influence of $\mathrm{pH}$ and temperature on growth and poly(3-hydroxybutyrate) production by the bacterial isolate B. cereus HAL 03 .

\subsection{Effect of $\mathrm{pH}$ and temperature}

The optimum $\mathrm{pH}$ and temperature for polymer accumulation coincide with those of growth of B. cereus HAL 03 . The highest growth and $\mathrm{P}(3 \mathrm{HB})$ accumulation were recorded at $\mathrm{pH}$ 7.6 and at a temperature of $37^{\circ} \mathrm{C}$ respectively (Figure 6). These findings confirmed the neutrophilic and mesophilic nature of the organism.

\subsection{Effect of aeration}

The effect of aeration on growth and $\mathrm{P}(3 \mathrm{HB})$ production was determined under shaking conditions with variation of culture volume per flask volume (CVF). Increase of CVF (which decreases the rate of aeration of the culture) in sucrose containing medium resulted in increase of biomass but significantly reduced the polymer accumulation (Figure 7). Growth of the organism was maximum at a CVF of 4:10 (40 ml medium/100 ml flask), while, highest $\mathrm{P}(3 \mathrm{HB})$ accumulation was recorded at a CVF of 2.5:10 (25 $\mathrm{ml}$ medium $/ 100 \mathrm{ml}$ flask). The increase in biomass at high CVF indicated efficient growth of the strain under oxygen stressed condition but sufficient supply of oxygen appeared to be an essential requirement for polyester synthesis and accumulation by HAL 03.

\subsection{Effect of non-conventional carbon sources}

Supplementation of growth medium with molasses of different types and malt extract $(2 \%, w / v)$ as sole source of carbon were tested for growth and accumulation of the polyester by $B$. cereus HAL 03. Light molasses significantly influenced the biomass formation $(2.75 \mathrm{~g} / \mathrm{l})$ and the production of $\mathrm{P}(3 \mathrm{HB})$ reached up to $1.49 \mathrm{~g} / \mathrm{l}$ with $\mathrm{P}(3 \mathrm{HB})$ content of $54 \%$ of $\mathrm{CDW}$ (Table 5). Sugarcane molasses, the by-products of sugar industry, therefore, could serve as the cheap non-conventional source of carbon along with vitamins and other minor constituents for effective and sustainable production of $\mathrm{P}(3 \mathrm{HB})$ by $B$. cereus $\mathrm{HAL}$ 03 similar to those of Alcaligenes eutrophus [33], Bacillus megaterium [34] and Bacillus sp. JMa5 [9]. 


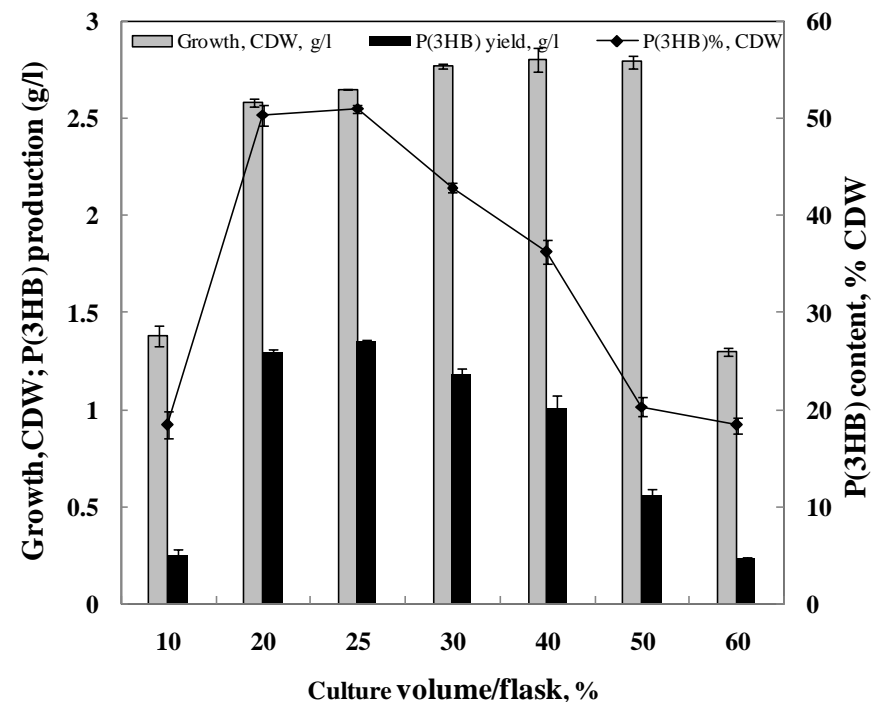

Fig. 7: Effect of aeration on growth and poly(3-hydroxybutyrate) production by the bacterial isolate B. cereus HAL 03

Table 5: Growth and production of poly(3-hydroxybutyrate) by the endophytic bacterium B. cereus HAL 03 using non-conventional carbon sources.

\begin{tabular}{lccc}
\hline \multirow{2}{*}{ Non-conventional carbon source } & \multirow{2}{*}{ Growth, CDW, g/l } & P(3HB), \% CDW & P(3HB) production \\
\cline { 3 - 4 } Purified molasses & $1.42 \pm 0.09$ & $51.02 \pm 2.04$ & $0.72 \pm 0.18$ \\
Light molasses & $2.75 \pm 0.32$ & $54.05 \pm 1.06$ & $1.49 \pm 0.33$ \\
Dark molasses & $2.40 \pm 0.08$ & $43.41 \pm 1.79$ & $1.04 \pm 0.14$ \\
Black strap molasses & $1.75 \pm 0.26$ & $48.30 \pm 0.93$ & $0.84 \pm 0.24$ \\
Malt extract & $2.28 \pm 0.43$ & $39.67 \pm 1.29$ & $0.90 \pm 0.15$ \\
\hline E &
\end{tabular}

Each value represents average of triplicate readings \pm SE; CDW $=$ Cell dry weight. The isolate, $B$. cereus HAL 03 was grown in mineral salts medium supplemented with different non-conventional carbon sources $(2 \%, \mathrm{w} / \mathrm{v})$ for $56 \mathrm{~h}$ at $32^{\circ} \mathrm{C}$ under continuous shaking. Growth was measured by cell dry weight and the $\mathrm{P}(3 \mathrm{HB})$ was extracted with chloroform from acetone dried cell mass and quantified according to Law and Slepeckey [27].

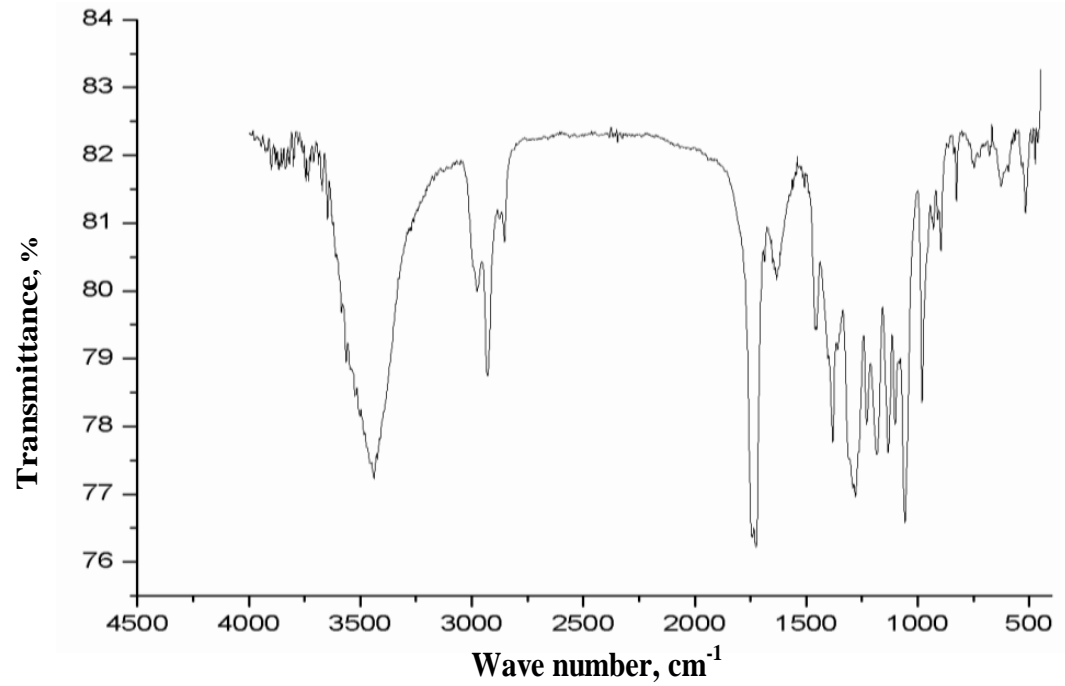

Fig. 8: Fourier-transform infrared (FTIR) spectrum of the polvmer extracted from the bacterial isolate B. cereus HAL 03

\subsection{FTIR and ${ }^{1} H$ NMR spectral analysis}

The identity of the intracellularly accumulated $\mathrm{P}(3 \mathrm{HB})$ was further confirmed by Fourier-transform infrared (FTIR) and proton nuclear magnetic resonance $\left({ }^{1} \mathrm{H}\right.$ NMR) spectral analysis. The FTIR spectra of the purified polyester (Figure 8) showed characteristic $-\mathrm{OH}$ 'bending at $3440 \mathrm{~cm}-1, \mathrm{C}-\mathrm{H}$ stretching at 2920$2980 \mathrm{~cm}^{-1}, \mathrm{C}=\mathrm{O}$ carbonyl bonds at $1720 \mathrm{~cm}^{-1}$ and $-\mathrm{CH}$ group of aldehyde at $1240-1370 \mathrm{~cm}^{-1}$ and provided evidence for the accumulation of $\mathrm{P}(3 \mathrm{HB})$ by the endophytic bacterium $B$. cereus HAL 03 [7, 21]. Likewise, the solution state ${ }^{1} \mathrm{H}$ NMR spectrum of the polymer (Figure 9) indicated chemical shifts at 1.2, 2.4-2.6 and 5.3 ppm corresponding to $\mathrm{CH}_{3}, \mathrm{CH}_{2}$ and $\mathrm{CH}$ groups respectively characteristics of 3-hydroxybutyric acid and thereby confirmed the homopolymeric nature of the polyester being composed solely of 3-hydroxybutyric acid [35]. 


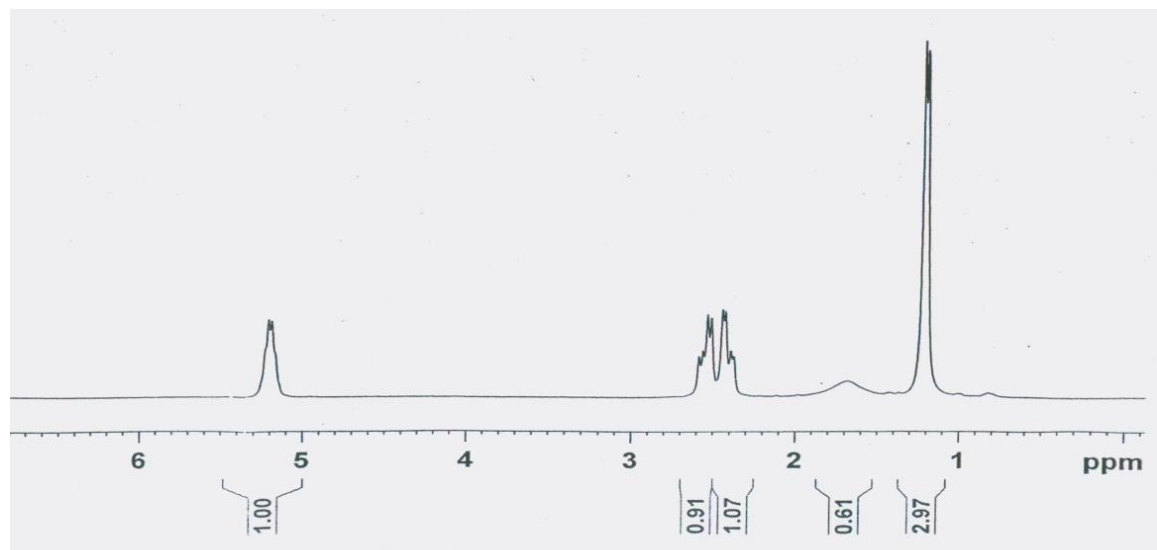

Fig. 9: Proton nuclear magnetic resonance spectrum of the polymer extracted from the bacterial isolate B. cereus HAL 03 .

\section{CONCLUSION}

Endophytes have been proven to be rich sources of novel natural compounds with wide spectrum of biological activities and high level of structural diversity. This study has clearly demonstrated that B. cereus HAL 03, endophytic to leaves of $H$. annuus L. could synthesize and accumulate biodegradable biopolyester, $\mathrm{P}(3 \mathrm{HB})$ and represents the first report of this kind. Production of $\mathrm{P}(3 \mathrm{HB})$ by the strain was further enhanced by optimization of cultural conditions and a considerable enhancement was recorded by using cost effective nonconventional carbon sources. These findings, therefore, deserve more detailed experimentation and analysis to ascertain the viability of this endophytic microbial resource for large scale production of poly(3-hydroxybutyrate) as an alternative to thermoplastics.

\section{ACKNOWLEDGEMENTS}

The research was supported by a grant (No. DST/INSPIRE Fellowship/2013/570) from the Department of Science and Technology, New Delhi, India to Rituparna Das. The authors are indebted to Prof. D. K. Maiti, Department of Chemistry, University of Calcutta and Dr. S. Chattopadhyay, Department of Chemistry, Jadavpur University for their invaluable assistance in characterization of the polymer.

\section{REFERENCES}

1. Steinbuchel A, Fuchtenbush B, Gorenflo V, Hein S, Jossek R, Langenbach S, Rehm BHA. Biosynthesis of polyesters in bacteria and recombinant organisms. Polymer Degradation and Stability. 1998; 59(1-3):177-182.

2. Anderson AJ, Dawes EA. Occurrence, metabolism, metabolic role and industrial uses of bacterial polyhydroxyalkanoates. Microbiological Reviews. 1990; 54(4):450-472.

3. Gasser I, Muller H, Berg G. Ecology and characterization of polyhydroxyalkanoate-producing microorganisms on and in plants. FEMS Microbiology Ecology. 2009; 70(1):142-150.
4. Fuchtenbusch B, Wullbrandt D, Steinbuchel A. Production of polyhydroxyalkanoic acids by Ralstonia eutropha and Pseudomonas oleovorans from oil remaining from biotechnological rhamnose production. Applied and Environmental Microbiology. 2000; 53(2):167-172.

5. McCool GJ, Fernandez T, Ning L, Cannon MC. Polyhydroxyalkanoate inclusion-body growth and proliferation in Bacillus megaterium. FEMS Microbiology Letters. 1996; 138(1):41-48.

6. Catalan AI, Ferreira F, Gill PR, Batista S. Production of polyhydroxyalkanoates by Herbaspirillum seropedicae grown with different sole carbon sources and on lactose when engineered to express the lacZ lacY genes. Enzyme and Microbial Technology. 2007; 40(5):1352-1357.

7. Kamnev AA, Antonyuk LP, Tugarova AV, Tarantilis PA, Polissiou MG, Gardiner PHE. Fourier transform infrared spectroscopic characterization of heavy metal-induced metabolic changes in the plant-associated soil bacterium Azospirillum brasilense Sp7. Journal of Molecular Structure. 2002; 610(1-3):127-131.

8. Forchetti G, Masciarelli O, Alemano S, Alvarez D, Abdala G. Endophytic bacteria in sunflower (Helianthus annuus L.): isolation, characterization, and production of jasmonates and abscisic acid in culture medium. Applied and Environmental Microbiology. 2007; 76(5):145-152.

9. Wu Q, Huang H, Hu G, Chen J, Ho KP, Chen GQ. Production of poly3-hydroxybutyrate by Bacillus sp. JMa5 cultivated in molasses media. Antonie van Leeuwenhoek. 2001; 80(2):111-118.

10. Valappil SP, Misra SK, Boccaccini AR, Keshavarz T, Bucke C, Roy I. Large-scale production and efficient recovery of PHB with desirable material properties, from the newly characterized Bacillus cereus SPV. Journal of Biotechnology. 2007; 132(3):251-258.

11. Chen GQ. Occurrence of poly-D(-)-3-hydroxyalkanoates in the genus Bacillus. FEMS Microbiology Letters. 1991; 84(2):173-176.

12. Arthi N, Ramana KV. Identification and characterization of polyhydroxybutyrate producing Bacillus cereus and Bacillus mycoides strains. International Journal of Environmental Sciences. 2011; 1(5):744-756.

13. Labuzek S, Radecka I. Biosynthesis of PHB tercopolymer by Bacillus cereus UW85. Journal of Applied Microbiology. 2001;90(3):353-357.

14. Caballero KP, Karel SF, Register RA. Biosynthesis and characterization of hydroxybutyrate-hydroxycaproate copolymers. International Journal of Biological Macromolecules. 1995; 17(2):8692.

15. Devi AB, Nachiyar CV, Kaviyarasi T, Samrot AV. Characterization of polyhydroxybutyrate synthesized by Bacillus cereus. International Journal of Pharmacy and Pharmaceutical Sciences. 2015; 7(3):140144. 
16. Yilmaz $M$, Soran $H$, Beyatli $Y$. Determination of poly- $\beta$ hydroxybutyrate (PHB) production by some Bacillus spp. World Journal of Microbiology and Biotechnology. 2005; 21(4):565-566.

17. Macrae RM, Wilkinson JF. Poly- $\beta$-hydroxybutyrate metabolism in washed suspension of Bacillus cereus and Bacillus megaterium. Journal of General Microbiology. 1958; 19(1):210-222.

18. Halami PM. Production of polyhydroxyalkanoate from starch by native isolate Bacillus cereus CFR06. World Journal of Microbiology and Biotechnology. 2008: 24(6):805-812.

19. Sharma P, Bajaj BJ. Production of poly- $\beta$-hydroxybutyrate by Bacillus cereus PS 10 using biphasic-acid-pretreated rice straw. International Journal of Biological Macromolecules. 2015; 79:704-710.

20. Hallmann J, Quadt-Hallmann A, Mahaffee WF, Kloepper JW. Bacterial endophytes in agricultural crops. Canadian Journal of Microbiology. 1997; 43(10):895- 914.

21. Reinhold-Hurek B, Hurek T. Living inside plants: bacterial endophytes. Current Opinion in Plant Biology. 2011; 14(4):435-443.

22. Gerhardt P, Murray RGE, Wood WA, Krieg NR. Methods for general and molecular bacteriology. Washigton DC: American Society for Microbiology; 1994.

23. Bauer AW, Kirby WMM, Sherris JC, Turck M. Antibiotic susceptibility testing by a standardized single disk method. American Journal of Clinical Pathology. 1996; 45(4): 493-496.

24. Marmur JA. A procedure for the isolation of deoxyribonucleic acid from microorganisms. Journal of Molecular Biology. 1961; 3(2):208218.

25. Saitou N, Nei M. The neighbor-joining method: A new method for reconstructing phylogenetic trees. Molecular Biology and Evolution. 1987; 4(4):406-425.

26. Ramsay BA, Lomaliza K, Chavarie C, Dube B, Bataille P, Ramsay JA. Production of poly-( $\beta$-hydroxybutyric-co- $\beta$-valeric) acids. Applied and Environmental Microbiology. 1990; 56(7):2093-2098.

27. Law JH, Slepeckey RA. Assay of Polyhydroxybutyric acid. Journal of Bacteriology. 1961; 82(1):32-36.

28. Miller GL. Use of dintirosalicylic acid reagent for determination of reducing sugar. Analytical Chemistry. 1959; 31(3):426-428.

29. Hong K, Sun S, Tian W, Chen GQ, Huang W. A rapid method for detecting bacterial polyhydroxyalkonates in intact cells by Fourier transform infrared spectroscopy. Applied Microbiology and Biotechnology. 1999; 51(4):523-526.
30. Das R, Pal A, Mandal S, Paul AK. Sreening and production of biodegradable polyester poly(3-hydroxybutyrate) by bacteria endophytic to Brassica nigra L. British Biotechnology Journal. 2015; 7(3):134-146.

31. Benoit TG, Wilson GR, Baugh CL. Fermentation during growth and sporulation of Bacillus thuringiensis HD-1. Letters in Applied Microbiology. 1990; 10(1):15-18.

32. Kominek LA, Halvorson HO. Metabolism of poly- $\beta$-hydroxybutyrate and acetoin in Bacillus cereus. Journal of Bacteriology. 1965; 90(5):1251-1259.

33. Beaulieu M, Beaulieu Y, Melinard J, Pandian S, Goulet J. Influence of ammonium salts and cane molasses on growth of Alcaligenes eutrophus and production of polyhydroxybutyrate. Applied and Environmental Microbiology. 1995; 61(1):165-169.

34. Gouda MK, Swellam AE, Omar SH. Production of PHB by a Bacillus megaterium strain using sugarcane molasses and corn steep liquor as sole carbon and nitrogen sources. Microbiological Research. 2001; 156(3):201-207.

35. Doi Y, Kawaguchi Y, Nakamura Y, Kunioka M. Nuclear magnetic resonance studies of poly(3-hyroxybutyrate) and polyphosphate metabolism in Alcaligenes eutrophus. Applied and Environmental Microbiology. 1989; 55(11):2932-2938.

\section{How to cite this article:}

Rituparna Das, Agnijita Dey, Arundhati Pal and A. K. Paul. Influence of growth conditions on production of poly(3hydroxybutyrate) by Bacillus cereus HAL 03 endophytic to Helianthus annuus L. J App Biol Biotech. 2016; 4 (04): 075-084. DOI: $10.7324 / \mathrm{JABB} .2016 .40409$ 